\title{
Dose-Time Effect of Crude Oil and Hydro-test Effluent on Freshwater and Brackish Water Habitats
}

\author{
${ }^{1}$ JOEL, O. F; ${ }^{2}$ AMAJUOYI, C. A; ${ }^{3}$ DEDE, E. B \\ ${ }^{1}$ Department of Petroleum and Gas Engineering, Faculty of Engineering, University of Port Harcourt, Nigeria. Ogbonna.Joel@yahoo.com; \\ 08052276568, 08037099211. \\ ${ }^{2}$ Pollution Control and Environmental Management Limited, Port Harcourt, Nigeria. Allwellcave@yahoo.com. \\ ${ }^{3}$ Department of Pharmacology and Toxicology, University of Port Harcourt.Eb_dede@yahoo.com.
}

\begin{abstract}
This work was undertaken to investigate the dose-time effect of crude oil and hydro-test effluent on freshwater and brackish water habitats. The species used for the acute toxicity were freshwater fish, Tilapia guineenis (fry) and a brackish water shrimp, Palaemonetes africanus. Test results indicated that the brackish water juvenile shrimps were more sensitive to the mixture of the hydro-test effluent and crude oil than the freshwater habitat. This could be attributed to the physicochemical constituents of the receiving environment. In both the freshwater and brackish water habitats, the higher the concentration and longer the exposure of the test species, the higher the mortality rate. This was evidenced from test result which showed $0 \%$ mortality for $100 \mathrm{mg} / \mathrm{l}$ at $4 \mathrm{hrs}$ for both the fresh water and brackish water species respectively, and $100 \%$ mortality at $4 \mathrm{hrs}$ for $100,000 \mathrm{mg} / \mathrm{l}$ concentration of the hydro-test effluent and crude oil mixture. The project therefore has provided a learning tool and a platform in evaluating the concentrations of the chemical and the duration of exposure required to produce the criterion effect. Moreover, test results validated the age long theory that 'the most important factor that determines the effect of any substance is the dose-time relationship. @ JASEM
\end{abstract}

Toxicology is the study of the adverse effect of chemicals or physical agents on living organisms. Because of the boundary conditions that create a bottle neck in determining the adverse effect of these chemicals, the most effective method to gauge effluent toxicity is to perform an effluent toxicity test that uses aquatic organisms as indicators of toxicity. A small, developing organism is an ideal model system for testing effluent toxicity. The developing organism exhibits rapid growth and sensitivity to the toxic material. Such tests are used in laboratories to ascertain the concentration of an effluent, usually expressed as a percent volume, which is lethal to $50 \%$ of the test organisms that are subjected to the effluent for a predetermined time period. This value is expressed as the Lethal Concentration 50 or the $\mathrm{LC}_{50}$.

The species used for the acute toxicity were a fresh water fish Tilapia guineenis (fry) and a brackish water shrimp, Palaemonetes africanus. These test organisms are recommended by DPR for toxicity testing of chemicals. The justification for the selection of the above organisms is based on their availability, sensitivity and relative ease of handling. The chemical analysis of an effluent cannot by itself predict its potential toxic effect. Many toxic pollutants cannot be detected by commonly available chemical analysis methods. The toxicity of many chemicals is unknown even when they can be detected. Different chemicals combined together in the same effluent can have unknown additive effects even when the toxicity of each individual chemical is well-known (Randall M., 1999; Ogbonna and Amajuoyi, 2009).

Toxicity tests are used to evaluate the concentrations of the chemical and the duration of exposure required to produce the criterion effect. Apparently, aquatic toxicity tests are used in detecting and evaluating the potential toxicological effects of chemicals (Okpokwasili and Odokuma, 1994) on aquatic organisms (Franklin, 1973). Toxicity tests became desirable in chemical quality evaluations as a consequence of the inability of the physical and chemical tests alone to sufficiently access the potential effect on aquatic biota (Powell et al., 1985). Furthermore, chemicals which by itselves would have been harmless may cause deleterious/synergistic effects by interacting in the general milieu of contaminated waters (Kingham, 1981). Our environment has been continuously subjected to the upstream activities of numerous petroleum based Industries. In most cases, the aquatic environments are the ultimate receivers of spill and other discharges. Most petroleum industries utilize various types of chemicals, which include low toxicity base oil, oil based mud system, drilling fluid, dispersants (Oyemo, 1986), and other chemicals as measure of drilling, reclamation and remediation.

The effect of any substance is dependent on a number of factors. The most important factor is the dose-time relationship. Dose is the quantity of a substance that a surface, plant, or animal is exposed to. Time means how often the exposure occurs. Thus, the dose- time relationship is how much of the substance is involved and how often the exposure to the substance occurs. 
This relationship gives rise to two different types of toxicity studies that applicators must know and understand. They are acute and chronic toxicity studies (Dede and Dogara, 2004; Dede, et al, 2002).

\section{MATERIALS AND METHODS}

\section{SEMI- STATIC BIOASSAY TEHNIQUES:}

Acute toxicity tests were carried out with aquatic organisms by exposing them (test organisms) to test solutions containing various concentrations of the test sample, using the semi-static agitation test procedure as recommended by Department of Petroleum Resources (DPR, 2002).

\section{SAMPLING TEST ORGANISMS:}

Fresh water fish Tilapia guineenis were collected from Mmiri Azu Ulo at Ohanso village near Akwete in Abia State. The fish were caught using nets at spring tide and were immediately transferred into 10L coolers containing the habitat water (APHA, 1998). Juveniles were collected because of their small size and sensitivity to toxicants.

Brackish water juvenile shrimp, Palaemonetes africanus were collected from the brackish water at Eagle Island Waterside, Port Harcourt. Juvenile shrimps were collected with the aid of sieves of appropriate mesh size during spring tide. They were transferred into $10 \mathrm{~L}$ coolers containing the habitat water (APHA, 1998).

Table 1: Average Weight of Test Organisms

\begin{tabular}{llll}
\hline S/n & Name of organism & Type of habitat & Weight of organism \\
\hline 1. & Tilapia guineenis & Fresh Water & $191 \pm 5 \mathrm{mg}$ \\
2. & Palaemonetes africanus & brackish water & $167 \pm 5 \mathrm{mg}$ \\
\hline
\end{tabular}

Table 2: Average Length of Test Organisms

\begin{tabular}{llll}
\hline $\mathrm{S} / \mathrm{n}$ & Name of organism & Type of habitat & Weight of organism \\
\hline 1. & Tilapia guineenis & Fresh Water & $2.5 \pm 0.5 \mathrm{~cm}$ \\
2. & Palaemonetes africanus & brackish water & $2.7 \pm 0.5 \mathrm{~cm}$ \\
\hline
\end{tabular}

\section{ACCLIMATIZATION PROCEDURE:}

All test organisms were first acclimatized for ten days at room temperature $28 \pm 2{ }^{\circ} \mathrm{C}$. They were acclimatized in dark glass tanks in which air (oxygen) was continuously bubbled into, through an aerator. They were also fed with fish feed obtained from the Institute of Fisheries at Aluu near University of Port Harcourt during the period of analysis. The water in the acclimatization units was replaced with the fresh water from the organism's habitat daily. There was controlled lighting system, as 12hours of light and 12hours of darkness was employed.

\section{Selection of Test Organism:}

Twenty test organisms of fairly equal size were randomly caught with a hand net from acclimatization tanks and carefully transferred into the test vessel. The organisms were not touched with hand during the selection so as to avoid stress due to handling. Only healthy and active test organisms were selected.

\section{Test Medium:}

Five different concentrations of the test sample (10mg/l, 100mg/l, 1000mg/l, 10, 000mg/l) were prepared using habitat water of the particular organism as diluent. This followed after a preliminary range finding test. Similar concentrations of crude oil (Bonny light), crude oil and test sample mixture (1:1), and a reference chemical, sodium lauryl sulphate (SLS) were also prepared using habitat water of the particular organism. . The corresponding aliquots were added to the test vessels constructed of glass. The aliquots were first stirred for 5 mins and subsequently at 8 hourly intervals.

Twenty test organisms were used in each concentration. Healthy, active test organisms were carefully introduced into bioassay vessels representing different concentrations. Controls containing dilution water, and twenty test organisms were prepared without the toxicant and this served as the control. Each of the test concentrations was labeled appropriately. After each day, the media were replaced with fresh one. Dead organisms were also removed at the end of each exposure period. This was done to avoid contamination of live organisms by bacteria from dead decaying organisms. Mortality was recorded at 4, 8, 24, 48, 72 and 96 hour exposure periods (Finney, 1978 and Sprague, 1973).

\section{RANGE FINDING TEST:}

Range Finding Test was carried out to establish a preliminary working range by obtaining the least concentration that gives no effect and the minimum concentration that gives $100 \%$ death. Test design incorporated multiple, widely spaced concentrations with single replicates. Exposure times were 4hr., 8hr., 24hr., and 48hr. 


\section{PHYSICO-CHEMICAL ANALYSIS:}

- $\quad$ pH, Temperature, Conductivity and Dissolved Oxygen:

These chemical properties were determined electrometrically with a multi- parameter data logger (Hanna model HI991300).

\section{- Salinity:}

Salinity was determined titrimetrically in accordance with APHA 2520A.

\section{- Alkalinity:}

Alkalinity was determined in accordance with ASTM D 1067B. This method involved titration of $100 \mathrm{ml}$ of sample against $0.01 \mathrm{M} \mathrm{HCl}$ with the addition of 2-3 drops of phenolphthalein indicator.

\section{- Hardness:}

Total hardness in water was determined in accordance with APHA 2340C. This method involved the addition of a standard EDTA solution to $50 \mathrm{ml}$ of the sample in $250 \mathrm{ml}$ conical flask. The mixture was stirred continuously until a reddish tinge disappeared and there was a color change to sky blue.

\section{- Total Suspended Solids:}

Total suspended solid (TSS) was determined with a membrane filter apparatus in accordance with APHA $2540 \mathrm{D}$. About $100 \mathrm{ml}$ of the water sample was filtered through dried pre- weighed $0.45 \mu \mathrm{m}$ filter paper and oven dried at $105 \pm 5^{\circ} \mathrm{C}$ for one hour. After which the paper was cooled in a desiccator and weighed. In order to obtain a realistic data devoid of salt interference from seawater, the filter apparatus after filtration of the seawater was thoroughly washed with distilled water. The determined residue was used to calculate the TSS.

Table 3: Some Physicochemical Characteristics of Two Dilution Water Types

\begin{tabular}{lll}
\hline Parameter & Freshwater & Brackish water \\
\hline $\mathrm{pH}$ & 5.50 & 7.20 \\
Temperature $\left({ }^{\circ} \mathrm{c}\right)$ & 26.1 & 25.4 \\
Conductivity (mg/l) & 158 & 3999 \\
Dissolved oxygen (mg/l) & 6.0 & 7.0 \\
Salinity (mg/l) & 97.35 & 1359 \\
Alkalinity (mg/l) & 17.1 & 1333.8 \\
Hardness (mg/l) & 20 & 80 \\
TDS (mg/l) & 29 & 2000 \\
\hline
\end{tabular}

\section{RESULT AND DISCUSSIONS}

Table 4: Dose-Time Effect of Different Concentrations Hydro-Test Effluent and Crude Oil for Freshwater Habitat

\begin{tabular}{lcccc}
\hline \multicolumn{5}{c}{ \% Mortality } \\
\hline Concentrations (mg/l) & 100 & 1000 & 10000 & 100000 \\
4 Hours & 0 & 0 & 10 & 100 \\
24 Hours & 0 & 5 & 80 & 100 \\
48 Hours & 15 & 15 & 100 & 100 \\
96 Hours & 25 & 20 & 100 & 100 \\
\hline
\end{tabular}

* Corresponding author: ${ }^{1}$ Joel, O. F. 


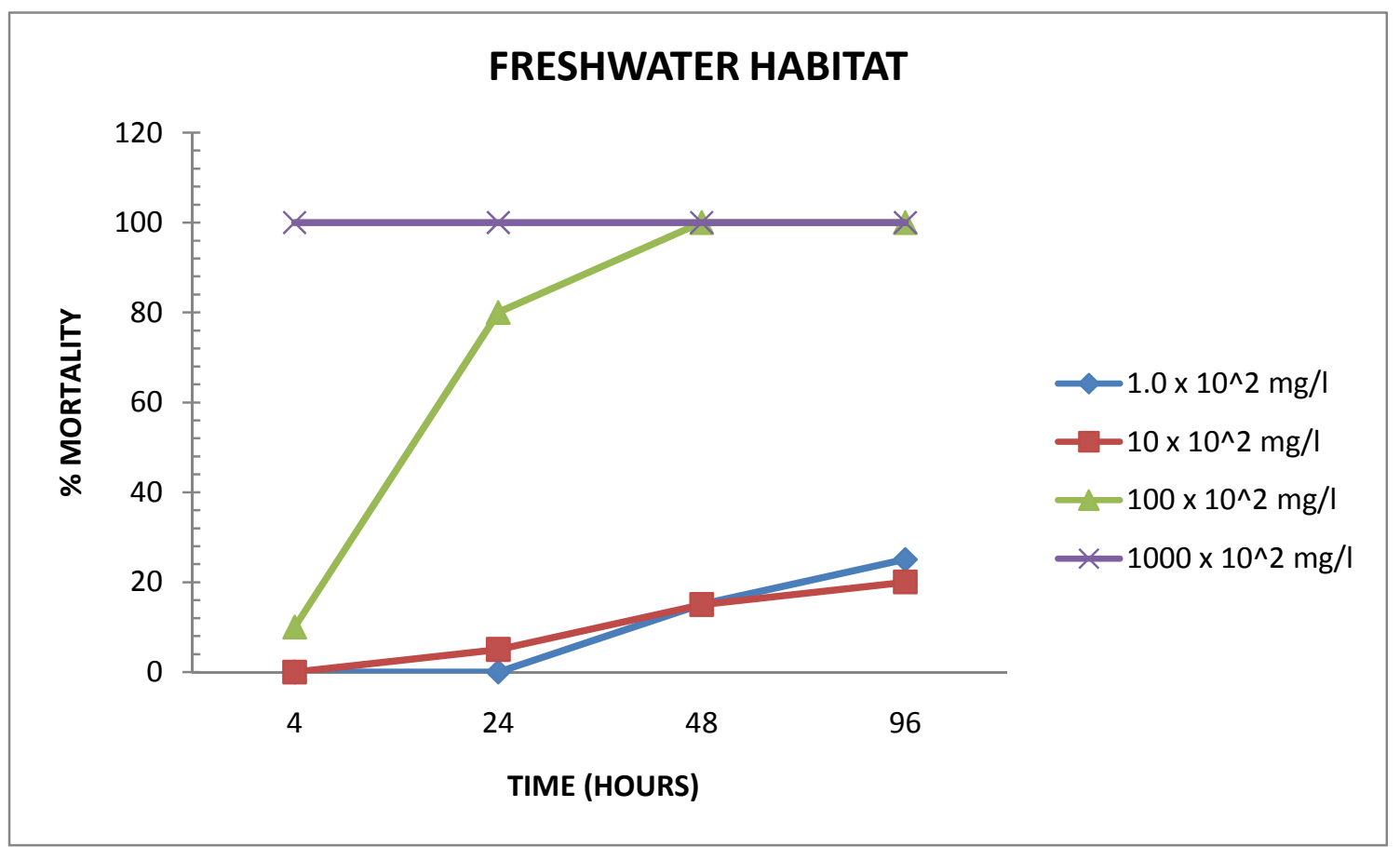

Fig 1: Dose- Time Effect of Hydrotest Effluent at Different Concentrations for Freshwater Habitat

Table 5: Dose-Time Effect of different Concentrations Hydro-test Effluent and crude oil for Brackish water Habitat

\begin{tabular}{lcccc}
\hline & \% Mortality & \\
\hline Concentrations (mg/l) & 100 & 1000 & 10000 & 100000 \\
4 Hours & 0 & 25 & 100 & 100 \\
24 Hours & 50 & 100 & 100 & 100 \\
48 Hours & 50 & 100 & 100 & 100 \\
96 Hours & 55 & 100 & 100 & 100 \\
\hline
\end{tabular}

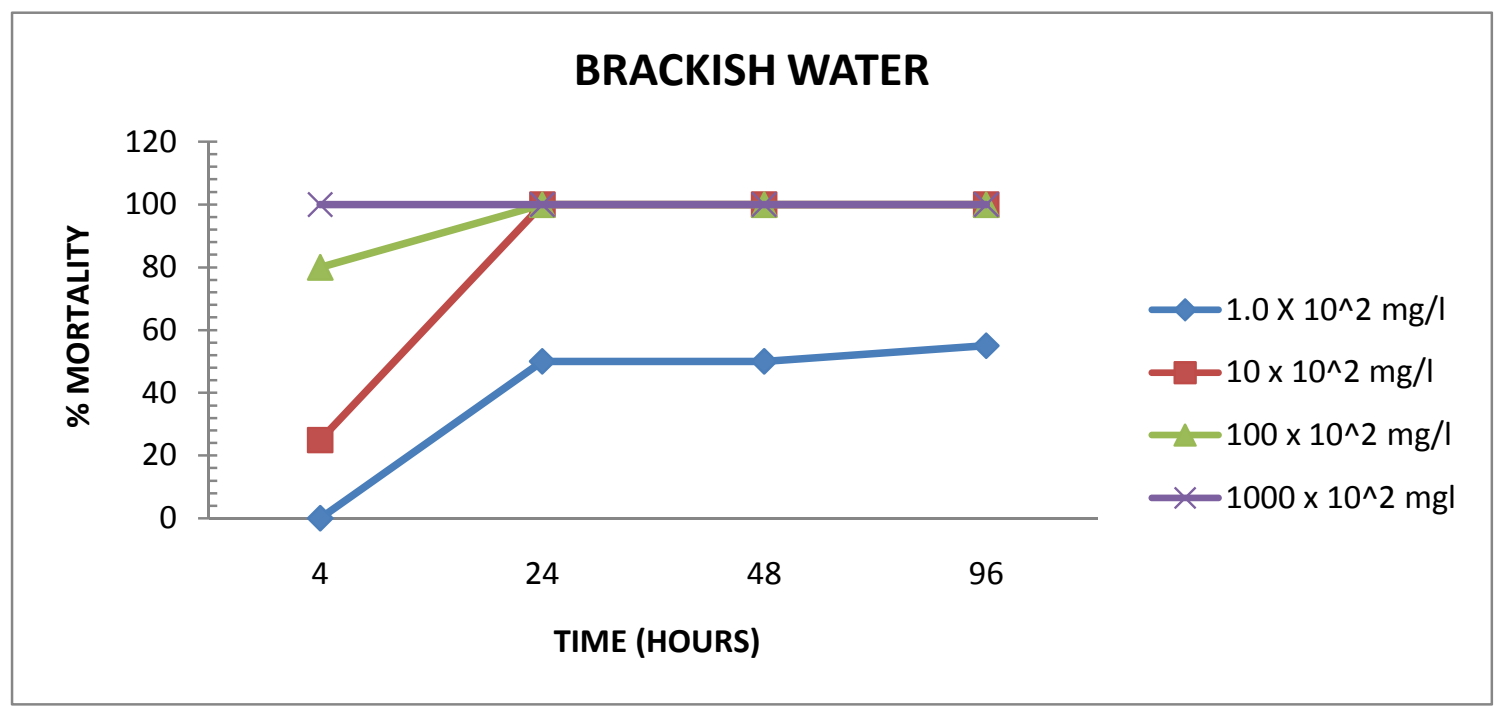

Fig 2: Dose- Time Effect of Hydrotest Effluent at Different Concentrations for Brackish Water Habitat

- Dose-time synergistic effect of the hydro-test effluent and crude oil on the receiving water

* Corresponding author: ${ }^{1}$ Joel, O. F. body resulted to increase in mortality rate of the 
organisms for both freshwater and brackish water habitat (table 4 and 5; figure 1 and 2).

- Both the fresh water and the brackish water organisms were sensitive to the mixture of the hydro-test effluent and crude oil. This resulted in $100 \%$ death of the organisms with respect to time.

- Dose - time effect indicated that the brackish water juvenile shrimp, Palaemonetes africanus were more sensitive to the mixture of hydro-test effluent and crude oil. Hence, at 8Hr interval, more deaths were recorded for the brackish water organisms. This could be attributed to the physicochemical constituents of the receiving environment (table 3).

Conclusion: The physicochemical constituents of the receiving environment also played a major role in determining the mortality rate of the aquatic organisms. The mortality rate was higher in the brackish water habitat than the fresh water habitat in all the concentrations tested. The semi- static bioassay revealed that the higher the concentration of the test chemical and crude oil with time, the higher the $\%$ mortality recorded.

This work will make for a better understanding of the concept of basic methods of chemical toxicity testing and as well has validated the age long theory that "the most important factor that determines the effect of any substance is the dose - time relationship.

\section{REFERENCE}

American Public Health Association (1998). Standard Methods for the Examination of Water and Wastewater $20^{\text {th }}$ Edition Edited by Andrew D. Greenberg et al.

Dede, E. B; Dogara, F. M. (2004). The Acute toxicological effect of Gamalin 20 (Gamma Isomer of Hexachlorocyclohexane) on the Lung and Pancrease of Guinea Pig. J. Appl. Sci. \& Env. Mgt. 8 (1) 33 - 35

Dede, E. B; Igboh, N. M; Ayalogu, O. E. (2002). Chronic toxicity study of crude petroleum (Bonny light), kerosene and gasoline in Rats using Haematological parameters. J. Appl. Sc. \& Env. Mgt. 6 (1) 60 -63.
Department of Petroleum Resources (2002). Environmental Guidelines \& Standards for the Petroleum Industry in Nigeria, pp 281-291

Duffs, J. H. (1980). Environmental Toxicology. Resources and Environmental Science Series. Edward Arnold Limited, London pp1-19.

Finney, D. J. (1978). Statistical Methods in Biological Assay 3rd Edition. Charles Griffin, London.

Franklin, F. L. (1973). Assessing the Toxicity of Industrial Wastes, with Particular Reference to Variations in Sensitivity of Test Animals / Fish. Rep MAFF Direct Fish Res., Lowerstoft.

Kingham, D.J. (1981). Oil Spill Chemicals, Environmental Implications and Use Policy for the Petroleum Industry and Nigerian Environment. Proceeding of the 1981 Seminar, NNPC pp 179 -184.

Ogbonna, F. Joel; Amajuoyi, Chinomso A. (2009). Synergistic Effect of Test Chemical with Crude oil Contaminated Aquatic Habitat, J.NES, 2009, Volume 5 Number three, Nigeria.

Okpokwasili, G. C; Odokuma, L. O. (1994). Toxicity of some Nigerian Crude Oils, Bulletin of Environmental Contamination and Toxicology 52: 388-399.

Oyemo, E. O. (1986). The Acute Toxicity of three oil dispersants. Environmental Pollution Ser. A, 41: 2331.

Powell, C.B; Baranowska, Dulkiewiz, B; Isoun, M; Ibiebele, D.D; Ofoegbu, F.U; White, S.A. (1985). Oshika Oil spill Environmental Impact; Effect on Aquatic Environment. Proceedings of the International Seminar on the Petroleum Industry and the Nigerian Environment. F.M.W. and H/NNPC, Kadunna 181-201.

Randall M. (1999). Whole Toxicity Testing and Limits, Department of Ecology, Water Quality Program, Sate of Washington, pp 173-205 WAC.

Sprague J.D. (1973). The ABC of Pollution Assays using Fish, Biological Methods for Assessment of Water Quality, A.S.T.M. STP 528, pp 6-30. 